\title{
VIOLÊNCIA, EDUCAÇÃO E SOCIEDADE: UM OLHAR SOBRE O BRASIL CONTEMPORÂNEO
}

\author{
ANGel PinO*
}

\begin{abstract}
RESUMO: Matéria diária dos noticiários nacionais, a violência tornou-se uma preocupação constante da população no Brasil. Não se trata de um fenômeno novo ou exclusivo do país, como o revela a história nacional e internacional, rica em eventos violentos. O que é novo são as formas inusitadas e destemidas com que ele se apresenta hoje no Brasil. O artigo tenta examinar alguns dos pontos mais importantes desse fenômeno. O primeiro diz respeito aos aspectos conceituais, mostrando os diferentes significados que definem a violência, o crime e a transgressão; discute-se também a relação da violência com a racionalidade. $\mathrm{O}$ segundo aborda a relação da violência com as condições históricas, sociais, econômicas e políticas da sociedade. O terceiro, enfim, discute o papel da educação, em geral, e da educação escolar, em particular, para preparar as novas gerações para um tipo de relações sociais que torne desnecessária a violência.
\end{abstract}

Palavras-chave: Violência. Violência e sociedade. Violência e educação. Violência no Brasil.

\section{VIOLENCE, EDUCATION AND SOCIETY: A LOOK ON CONTEMPORANEOUS BRAZIL}

ABSTRACT: A daily topic in the Brazilian press, violence has become a constant concern for Brazilians. Rich in violent events, both Brazilian and international histories clearly show this phenomenon is neither new nor exclusive to Brazil. Novelty lies in the uncommon and daring forms it nowadays takes on in this country. This paper explores some of the most important ones The first one regards the conceptual aspects and shows the different meanings that define violence, crime and transgression; the violence-rationality relation is

Doutor em Psicologia, professor livre-docente (aposentado) pela Universidade Estadual de Campinas (UNICAMP) e docente-pesquisador do Mestrado em Educação da Universidade do Vale do Itajaí (UNIVALI). E-mail: apino@unicamp.br 
also discussed. The second one approaches the issue of the relation between violence and the historical, social, economical and political conditions of society. The last one discusses the role of education in general and of school education in particular to prepare the new generations to a kind of social relationships that makes violence unnecessary

Key words: Violence. Violence and society. Violence and education. Violence in Brazil.

\section{Introdução}

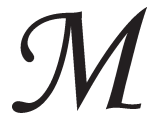

atéria diária de alguns anos para cá dos noticiários nacionais da imprensa e da televisão, a questão da violência tornou-se uma das principais preocupações, senão a principal, das pessoas no Brasil, como vêm mostrando-o algumas pesquisas nacionais de opinião pública. A exposição intensiva às notícias de fatos ditos violentos, os quais cobrem um amplo espectro de situações diferentes, reforça na população em geral a idéia de que a violência anda solta no país e de que há pouco a fazer contra ela, dada a insuficiência e ineficácia das medidas tomadas pelos poderes públicos. A imprevisibilidade das ações violentas e a crescente consciência da impotência frente a elas estão gerando no imaginário coletivo e individual a representação da violência como uma força cega e incontrolável, diante da qual a única postura "racional" acaba sendo a lei do silêncio e a submissão às exigências do terror. Não se trata, bem entendido, de um fenômeno novo ou exclusivo do Brasil, pois a história contemporânea, nacional e internacional, está semeada de acontecimentos violentos. Realmente novas são as formas inusitadas e destemidas com que a violência se apresenta atualmente entre nós, com consequências imprevisíveis. Se a natureza e as dimensões reais do fenômeno da violência ainda não estão suficientemente esclarecidas, são bem conhecidas já as transformações que ele vem produzindo nos hábitos e práticas sociais das pessoas e nas virtudes que as fundamentam. $\mathrm{O}$ vírus da violência penetra nos poros do tecido social, ameaçando a saúde moral das instituições nacionais.

O fenômeno da violência é suficientemente complexo para resistir às análises superficiais que por vezes são feitas dele. Ele envolve questôes sociais, econômicas e políticas nacionais mal resolvidas ou ainda não resolvidas. Não tenho a pretensão de abordar um fenômeno tão 
complexo como este, mas apenas discutir alguns de seus pontos específicos nos limites de espaço de um artigo: 1) aspectos semânticos e conceituais que a palavra violência levanta; 2) questôes mais importantes que esse fenômeno suscita, tal como se apresenta hoje no Brasil; 3) alguns parâmetros de compreensão do seu impacto no campo da educação, em geral, e da educação escolar, em particular.

\section{O conceito de violência: problemas semânticos}

Uma das maiores dificuldades no tratamento da violência, mais precisamente das ações ditas violentas, é a imprecisão dos seus contornos semânticos. Várias são as razões disso. Uma, de caráter mais psicológico, é que elas são assim denominadas, com freqüência, muito mais pelo impacto emocional que produzem no imaginário das pessoas do que por razões objetivas consistentes. Outra razão, de caráter mais filosófico, é a dificuldade de encontrar um princípio racional que explique essas ações, particularmente sob o impacto emocional dos seus efeitos. Outra, de caráter mais antropológico, é que a qualificação das ações como violentas permite desqualificar seus autores, tornando-os a expressão máxima da desumanidade, rebaixando-os, equivocadamente, ao nível da animalidade, mundo onde não há lugar para a violência por não existir nele liberdade, intencionalidade, nem consciência, todas elas características da condição humana dos homens.

Se toda palavra é por natureza polissêmica, susceptível de múltiplos sentidos, há algumas em particular que adquirem um sentido tal que lhes confere um potencial evocativo capaz de provocar intensas reações racionais ou emocionais nas pessoas. Este parece ser o caso da palavra violência e dos adjetivos correspondentes, cujo poder evocativo faz com que a força do seu sentido seja maior que a do seu significado. $\mathrm{O}$ sentido se alimenta da experiência coletiva da humanidade, extremamente rica em fatos violentos, em que o imaginário de certos indivíduos encontra farto material para alimentar seus devaneios destrutivos. Já o significado está delimitado pela própria história da língua registrada, em parte, nos dicionários. Os significados que o Dicionário da Língua Portuguesa (Buarque de Holanda, 1975) atribui à palavra "violência" não traduzem a densidade semântica que ela adquire no imaginário coletivo. $\mathrm{O}$ primeiro deles define a violência como a qualidade de violento, formulação tautológica que confere ao termo "violento" um estatuto 
ontológico indefinido, espécie de entidade mitológica que ajuda a alimentar o imaginário coletivo e individual. Outros significados que explicitam essa qualidade são impeto, exercício da força bruta, tumulto, irascibilidade e intensidade. O sentido que perpassa todos esses significados, na sua heterogeneidade, é o de excesso, aspecto quantitativo que tanto pode traduzir a representação de um certo grau de intensidade desnecessária da ação ou dos meios utilizados para realizá-la - a dificuldade é a imprecisão e o caráter relativo do termo "desnecessária" -, quanto pode traduzir a violação dos limites estabelecidos pelas leis, os valores ou as tradiçôes sociais. O sentido de excesso tanto é atribuído a certos eventos naturais (cataclismos, tornados, tempestades, terremotos etc.), quanto a certas ações humanas (massacres, genocídios, uso de armas de destruição em massa, devastação das florestas etc.). Tratandose de fenômenos naturais, falar de excesso só pode ser em sentido metafórico, como projeção do impacto que eles podem produzir em nós. Tratando-se das ações humanas, onde esse sentido de excesso se aplica, mais do que significar intensidade física, até certo ponto irrelevante do ponto de vista conceitual, ele significa violação dos limites estabelecidos pela sociedade, revelando no seu autor uma espécie de "vontade de poder" irrefreável, que o coloca acima de qualquer limite ou lei. Há filósofos e antropólogos que vêem a violência como uma característica própria do mundo sagrado (Makarius, 1974; Girard, 1972; Caillois, 1950) no qual, em contraposição ao mundo profano, onde reina a ordem e a lei, não existe, por definição, nem lei nem ordem. Ao fazer da própria "vontade de poder" o limite da violência, o homem coloca-se fora da lei e da ordem, num lugar que não é seu e com um poder sagrado que ele não pode ter. Infelizmente, não se trata de um mero "delírio da mente", mas de fatos com consequências sociais reais!

Um último significado apontado pelo dicionário para a palavra violência é o que é contra o direito e a justiça, entendendo estes dois termos mais como valores sociais e culturais do que como instituiçôes sociais, já que, enquanto tais, o Direito e a Justiça podem tornar-se instâncias da própria violência, a chamada "violência institucional", da qual a história humana fornece inúmeros e dramáticos exemplos. Considerados como valores, o direito e a justiça podem ser entendidos como interdependentes, pois, de um lado, o direito das declarações políticas ou sociais - como a dos "direitos do cidadão" da Revolução Francesa e a dos "direitos humanos" da ONU - define o campo do que é ou não é 
justo, podendo dar origem a delimitações positivas em forma de leis (códigos civil e penal) e, de outro lado, a justiça define o campo do respeito dos direitos humanos e do cidadão. Entretanto, a violação dos direitos e da justiça como valores não constitui, necessariamente, um ato de violência, embora possa constituir um delito ou crime.

\section{Violência, crime e agressão}

O conceito de violência é associado com relativa freqüência aos de crime e agressão, sendo usados indistintamente, o que pode dar origem a graves equívocos, não só porque significam coisas distintas, mas também porque essa prática pode mascarar objetivos de natureza ideológica. Crime é um conceito de natureza legal que, em si mesmo, significa apenas um ato de transgressão da lei penal, o que assujeita seu autor a penas legais variáveis segundo as sociedades. Enquanto ato de transgressão, o crime não tem, em si mesmo, qualquer conotação de violência física, social ou moral, embora possa ser agregada a alguns desses atos em razão da forma de que eles se revestem. A partir do Código Penal napoleônico (1810), a tradição jurídica reconhece o princípio da responsabilidade criminal, contra as arbitrariedades do poder, e vai introduzindo nos códigos penais modernos as circunstâncias agravantes e atenuantes que, sem retirar do ato seu caráter criminal, alteram o grau de responsabilidade penal do seu autor. Dentre as primeiras, podem ser lembradas a existência clara de violência e crueldade, a ofensa a certos valores sagrados, as características da vítima etc. Dentre as segundas, podem ser citadas a evidência de ausência de intenção ou liberdade, a deficiência mental, a legítima defesa etc. Um caso particular é a condição de "menoridade penal" do autor do crime, variável em cada sociedade. No Brasil, o Estatuto da Criança e do Adolescente (ECA), promulgado em outubro de 1990, estabelece os 18 anos como limite da menoridade penal. Tal condição torna as crianças e os adolescentes autores de atos contrários à lei penal "legalmente inimputáveis", a saber: embora exista a configuração legal do ato, seus efeitos penais não se aplicam ao seu autor, sendo indicadas no próprio Estatuto outras medidas sócio-educativas adequadas em cada caso (Pino, 1990). Pode-se concluir então que o significado de crimes do mesmo gênero pode ser diferente em cada caso, em razão das circunstancias em que ocorrem.

O conceito de agressão, por sua vez, traduz tecnicamente uma disposição natural dos organismos mais evoluídos para o ataque e a defesa, 
quando determinados sinais físicos emitidos por outros organismos são "interpretados" como ameaça à própria sobrevivência. Como tal, o termo se aplica aos organismos animais e humanos. Mas, enquanto em aqueles essa disposição é regulada por mecanismos genéticos de natureza instintiva, nestes é subordinada às leis históricas da cultura, que passam a regular seus impulsos naturais na realização das ações humanas. A natureza cultural do homem lhe confere a capacidade de atribuir significação às ações, cujo caráter polissêmico lhe impõe a necessidade de interpretálas antes de decidir realizá-las ou não, mesmo quando as circunstâncias sociais em que está envolvido despertem nele impulsos agressivos de origem natural (sub-cortical), pois estes passam, necessariamente, pelo controle das áreas corticais do cérebro, sede das atividades de interpretação e de decisão. Portanto, não se justifica qualificar de "animais" as reações agressivas, criminosas ou violentas do homem.

Conclui-se que, consideradas as significações conceituais específicas de cada um desses termos - agressão, crime e violência - e as condiçôes particulares que as determinam, é incorreto utilizá-los indistintamente, como se fossem sinônimos, pois se referem a fenômenos muito diferentes. É claro que existem inúmeros atos de agressão que são praticados de forma violenta; mas existem muitos outros que não o são. É evidente também que, enquanto transgressão da lei penal, o crime não implica necessariamente agressão física ou moral (como nos chamados "crimes sem vítima"), nem violência (como nos chamados "crimes de colarinho branco"); mas é também evidente que muitos crimes envolvem agressões físicas e veiculam formas claras de violência. É sabido também que atos tão graves como o homicídio, embora constituam transgressão da lei penal, nem sempre constituem um crime, nem são sempre realizados de maneira violenta. Finalmente, existem atos não considerados violentos que são a expressão pura da violência, como nos casos da chamada "violência simbólica" e em muitos outros de "violência institucional". E o que é mais grave, não só podem não ser considerados crimes ou objeto de repúdio como, em certos casos, podem ser até valorizados por alguns segmentos sociais ou grupos específicos.

\section{Violência e racionalidade}

Outro problema no estudo da violência é sua relação com a racionalidade. Os atos violentos mais graves, como os praticados com 
requintes de crueldade, são vistos por alguns autores e alguns setores da mídia e da opinião pública como atos irracionais, seja porque escapam ao controle da razão, seja por ver neles a expressão de tendências desumanas resultado de uma maldade inerente à natureza da pessoa.

Ora, se a violência é irracional, não é por ser obra de um ser desprovido de razão, mas por ser, paradoxalmente, o produto de uma razão perigosamente racional. É o que ocorre quando certos mecanismos racionais, como a "simplificação", que reduz tudo a um único princípio explicativo, e a "polarização", que vê a realidade como feita unicamente de elementos antagônicos e irreconciliáveis (Hacker, 1972), deixam o indivíduo sem alternativas. Esses mecanismos traduzem a racionalidade de uma razão incapaz de lidar com os antagonismos, as diferenças e a diversidade. Portanto, o problema que levanta a violência é muito menos o da irracionalidade do que o de uma racionalidade repleta de "razões" para não se deter diante de limites e de regras estabelecidas pela própria razão humana. É a razão que, amplificando os conflitos e reduzindo as alternativas ao impasse, superdimensionando os defeitos dos outros e profetizando catástrofes com a mobilização das simbologias mais eficazes, cria os cenários onde florescem as ideologias legitimadoras da violência. Em outras palavras, o problema da violência está intimamente ligado ao problema das relações sociais, em que a existência do outro aparece como ameaça real ou imaginária à própria existência (física, social ou psicológica). O que mais espanta na fenomenologia da violência, quando ela é razão de espanto, é muito mais a sua dramaturgia, a exposição da crueldade ao estado puro, do que a sua significação. É o caráter aparentemente absurdo dessa dramaturgia que confere à violência o status de irracionalidade. No entanto, as razões dessa irracionalidade raramente são explicitadas e, freqüentemente, deixam de existir quando o autor desses atos é o "inimigo" ou alguém que pode comprometer os interesses de alguns. Ficase estarrecido, por exemplo, perante o ritual da tortura, sendo difícil imaginar que possa existir uma razão lógica que a justifique. Entretanto, basta identificar o torturado para que os autores desse macabro ritual encontrem razões racionais suficientemente poderosas para justificá-lo.

Como o zoólogo K. Lorenz (1969), muitos já se perguntaram: "Por que os seres doados de razão se comportam de maneira tão pouco racional?”. Questão difícil de responder, já que a resposta constitui um 
paradoxo, pois a mesma razão invocada como condição da violência é excluída como sua explicação. Se só o ser racional pode agir irracionalmente, então a chave do enigma da violência está na própria razão. Segundo as análises de Foucault (1972), a experiência de uma "razão louca" e de uma "loucura razoável" era familiar à Renascença, sendo no racionalismo cartesiano do século XVIII que a loucura deixa de ser uma experiência dramática de crítica da razão para tornar-se manifestação do erro. Tempos depois, a psiquiatria nascente do século XIX introduz os estranhos conceitos de moral insanity, de Prichard (1835), e de folie morale, de Esquirol (1838). A idéia de uma "loucura da mente" é substituída por uma "loucura moral", sem alteração das funções mentais. Essas visões tão diferentes do ser humano e de suas ações que a modernidade forjou inscreveram, definitivamente, a violência humana nos registros da irracionalidade da mente e da patologia moral dos "instintos sociais". A violência caiu na esfera do irracional não só por falhas da razão, mas pela sua perversão. Isso constitui uma grande dificuldade para compreender esse fenômeno que se junta a outras, algumas das quais já foram vistas anteriormente.

Uma é o caráter relativo do conceito de violência e as diferentes formas com que esse fenômeno se apresenta. Embora as formas físicas sejam as que mais chamam a atenção pela sua dramaticidade, as simbólicas se revelam mais perversas, pois atingem o homem no seu próprio ser. É o caso, por exemplo, das várias formas de exclusão social que se perpetuam historicamente, afetando milhões de habitantes aos quais se nega na prática os direitos humanos fundamentais reconhecidos na teoria. Ou, ainda, desse tipo de violência implícita no meio rural - mais freqüente no passado, mas ainda presente hoje - desses "senhores da terra" que, por meio de um subtil mecanismo de relações sociais, perpetuavam seu senhorio sobre os seus "servos" (os colonos), fazendo com que a submissão se tornasse "desejo de submissão" (Lagendre, 1974).

Outra, legado do pensamento positivista, é atribuir o estatuto ontológico a simples qualidades das ações. Fala-se assim de crime, de agressão e de violência como se fossem entidades em si, independentes dos seus processos de produção e atribuição de significação por parte da sociedade. Um efeito perverso disso é a prática de transformar "certos" autores de crimes e de atos violentos - sim, porque não se aplica a todos - em personagens cuja rotulação de "criminoso", "bandido", 
"violento" ou "psicopata" qualifica não tanto as açôes quanto o seu ser. Uma prática que nos transposta ao século XIX, ao tempo de L'uomo criminale (1876) de C. Lombroso (1835-1909), que encontrava o "ser criminoso" nas formas anatômicas dos condenados por crime.

Uma última dificuldade é o fato do fenômeno da violência apresentar diversas dimensões, como ocorre na divisão que se faz entre violência expressiva, aquela cujo objetivo é infligir algum tipo de mal a alguém, e violência instrumental, vista como um simples meio normal para atingir um determinado fim social (estima, status, poder etc.), de forma que o mal que ela pode ocasionar é considerado uma mera consequência e não um objetivo da ação. Enquanto a primeira é considerada ilegal e socialmente inaceitável, a segunda é considerada legal e socialmente aceitável (Ball-Rokeach, 1980, p. 45-82).

\section{Um olhar sobre o Brasil contemporâneo}

Discutidas as questôes conceituais que o fenômeno do tema da violência levanta, o olhar se volta sobre o Brasil contemporâneo, subtítulo deste texto, no intuito de tentar compreender alguma coisa desse fenômeno que assola o país nos dias de hoje. O termo "contemporâneo" é pensado como um delimitador do tempo em que se situa o fenômeno de que se está falando e como um indicador da sua natureza histórica.

A violência que se vive hoje no Brasil não vem do nada, nem de fatores que não sejam já conhecidos, embora possam ser ignorados. Longe de ser um acidente na história nacional, ela tem tudo a ver com certas características da história social e econômica brasileira, não podendo ser atribuída, ingenuamente ou ideologicamente, nem a perturbações intempestivas da consciência de alguns indivíduos, nem a uma repentina mudança das condições do país. Com efeito, cabe perguntar-se: Qual é o grande objetivo do tráfico nacional de drogas e de armas, mesmo quando está afiliado à máfia internacional? Por acaso, seria simplesmente o resultado de mentes perversas que têm o prazer de corromper as pessoas por meio do consumo e dependência de drogas, ou de alimentar com o contrabando e tráfico de armas as guerras intestinas existentes em certas regiões distantes do mundo? Embora existam hoje finalidades claramente políticas que expliquem esses fatos, em razão dos graves e variados tipos de conflitos, internacionais ou nacionais, que envolvem ações bélicas e reaçóes terroristas, é sabido que o grande objetivo do tráfico de armas e do narcotráfico 
no Brasil contemporâneo, como em outros países, é de natureza econômica. Trata-se da posta em prática de formas de construir um capital patrimonial, praticando um capitalismo selvagem de renda fácil e recorrendo a todos os meios necessário para isso, legais ou ilegais, desde que sejam eficazes. Eis a grande questão que parece passar surpreendentemente despercebida na discussão desse fenômeno, a qual é movida frequentemente pela reação emocional que produz a percepção das cenas de horror de certos fatos "absurdos" e inéditos, como no trágico evento que vitimou o menino João Hélio, no Rio de Janeiro, no dia 7 de fevereiro deste ano! Esses legítimos sentimentos de horror não podem, entretanto, ocultar a razão que orienta a intensa prática da violência numa sociedade capitalista, em que o principal "mal" para o mundo dos negócios é não respeitar as regras do jogo, ou seja, "jogar sujo", despertando assim a reação social. Foi dessa forma que as atividades mafiosas dos séculos passados viram arruinarem-se seus negócios. As mortes, os massacres, a destruição de lares, a produção de uma legião de dependentes com seqüelas patológicas sérias etc. tudo isso preocupa, sobretudo, aos que estão fora do mundo dos negócios ou que, estando dentro, consideram que essas formas "selvagens" os prejudicam. O que aconteceria ao narcotráfico se o valor dos produtos traficados se depreciasse, a tal ponto que o acesso a eles fosse tão fácil como o acesso a outros produtos de uso diário? Bem, isso é hoje impensável, pois significaria descriminalizar sua venda e consumo, o que ofenderia a consciência moral dos bons cidadãos!

É esse o sentido do "olhar" que se busca aqui ao tratar a violência no Brasil contemporâneo, voltando esse olhar para alguns dos aspectos que considero mais importantes desse fenômeno, tentando estabelecer algumas relaçóes entre os fatos e os problemas conceituais acima discutidos. Nesse intuito, serão discutidas algumas questôes referentes às relaçôes entre "violência e sociedade", de um lado, e entre "violência e educação", do outro, argumentando que, "se a educação não é a solução para acabar com a violência, sem educação a violência não tem solução, nem a curto nem a longo prazo”. Eis o paradoxo. Mas tudo depende de como entendemos a educação.

\section{Violência e sociedade}

Colocar a questão da relação que possa existir entre violência e sociedade é uma tarefa complexa. Primeiro, porque estabelecer essa relação 
supõe a existência de alguma concepção a respeito do que se entende por cada um desses termos, consciente de que, dependendo da concepção que se tenha deles, o "olhar" sobre eles e sobre a sua relação não será o mesmo. Segundo, porque estamos diante de duas realidades históricas a sociedade e o fenômeno da violência - que, sendo categorias teóricas diferentes e aparentemente independentes, na práxis estão interligadas, pois, como já foi dito, não há sociedade humana sem a possibilidade da violência e não existiria violência se a sociedade não fosse humana. Terceiro, porque, colocada a questão nos termos enunciados acima, somos conduzidos a outra questão de fundo que é a concepção que se tem da relação indivíduo ó sociedade. Creio que essa concepção explique as anteriores. Tudo isso mostra por que é tão complexa a questão, aparentemente tão simples, da relação violência ó sociedade.

Coerente com a linha de pensamento que orienta este trabalho, o meu "olhar" sobre a questão da violência parte de uma concepção de homem e de sociedade que tem alguns pressupostos de base implícitos na forma de relacionar os vários temas. Brevemente, podem ser sintetizados em dois: (1) no mundo animal, a sociabilidade, sob as múltiplas formas em que se apresenta, é um fenômeno natural, regido por determinantes genéticos próprios a cada espécie e pelas condiçóes ambientais em que elas vivem ao longo da sua evolução e que implicam adaptações para conseguir a sobrevivência. Essa sociabilidade natural constitui, para o ser humano, pelas suas origens no reino animal, o fundamento de qualquer forma de organização social humana possível e que a história mostra terem sido várias; (2) que essas formas de organização social são obra do próprio homem e que, portanto, não são mais regidas, exclusivamente, por determinantes naturais, mas por determinantes de natureza histórica, qualquer que seja a fonte real de onde elas emanam. Em outras palavras, é próprio da natureza humana ou cultural dos homens determinar a maneira como eles se organizam enquanto seres sociais, estabelecendo os princípios, regras, normas ou leis que definem as formas de organização social, não ignorando que o coletivo humano não é um todo homogêneo, mas feito de conflitos e de interesses diferentes. Isso quer dizer que, no mundo bumano, os impulsos agressivos naturais continuam existindo, sim, mas regulados por mecanismos sociais de origem cultural e que tanto os impulsos, quanto esses mecanismos de controle têm significação para o indivíduo.

Parece ser consensual que, na nossa cultura, a idéia de violência evoca a imagem das turbulências, dos movimentos telúricos e das forças 
naturais desenfreadas que ameaçam submergir tudo no caos, o que conduz facilmente à idéia de que a violência leva ao "caos" social ou moral. Ora, o conceito de Caos escapa à nossa inteligibilidade, herdeiros que somos, como diz Morin (1973), de um tipo de pensamento em que Logos é o discurso da ordem e da regra. No antigo pensamento grego, Caos designava o estado primordial do universo, uma sorte de pré-universo monstruoso onde não existia nem ordem ou lei (Dikè), nem desordem ou desmedida (Ubris). É um estado que precede o Cosmos, universo organizado onde reina a regra e a ordem. Isso explica por que a estrutura lógica do nosso pensamento tende a associar a idéia de racionalidade às de ordem, limite e lei e a de irracionalidade, às de desordem, desmedida e ilegalidade.

No pensamento moderno, a violência evoca a idéia de desordem: "desordem da razão", "desordem moral" e "desordem social", as quais têm em comum o fato de fazerem do indivíduo a origem e causa dessas desordens. Mas a história social moderna, mais especificamente nas sociedades burguesas surgidas, particularmente, da Revolução Inglesa (s. XVII) e da Revolução Francesa (s. XVIII), revela que isso não se aplica a todos os indivíduos, mas apenas ou principalmente a alguns, os oriundos das classes populares, cidadãos sem cidadania por não terem propriedade. Essas classes são vistas desde então como a causa e origem do crime e da violência na sociedade, das quais esta tinha que se proteger, inventando a "prisão". Sob a influência dos movimentos sociais do fim do século XIX e do pensamento marxista, certos estudos criminológicos da segunda metade do fim do século passado ${ }^{1}$ apontam a ordem social burguesa como a raiz última do crime e da violência na modernidade. Se a violência é um fator desestabilizador da ordem social, ela é também um fator de crítica e questionamento dessa ordem. $\mathrm{Na}$ medida em que toda ordem social constitui um determinado modo de ordenamento das relaçôes econômicas, sociais e políticas de uma dada sociedade, a violência social, enquanto violação dos limites definidos por essa ordem, representa efetivamente um fator de desestabilização. Mas, por essa mesma razão, ela coloca a questão da legitimidade dessa ordem, pois se a legitimidade de uma determinada ordem social retira a razão à violência, a sua ilegitimidade - seja por causa da negação do estado de direito, seja pelo não cumprimento de suas exigências - dálhe razão. O assunto é extremamente importante, particularmente se olhado pelo ângulo dos acontecimentos que estão sendo vividos nos últimos anos no Brasil, mas ele extrapola os objetivos deste trabalho. 
Embora todo ato de violência tenha uma dimensão social, existem alguns deles em que a violência parece se esgotar no próprio ato, sem outras conseqüências sociais. Existem outros, porém, em que a violência atinge o corpo social como um todo, provocando o repúdio e a reação de determinados setores da sociedade e dando origem, em certas situações, a reaçôes igualmente violentas. É o caso dos confrontos de grupos ou movimentos sociais com a repressão policial, ou das insurreições sociais, ou dos conflitos religiosos, entre outros. Nestes casos, fala-se com toda propriedade de "violência social", algo que efetivamente põe em questão a ordem social. A principal característica da violência social é ser de natureza instrumental, por visar a determinados fins políticos e/ou sociais e por usar meios físicos para sua concretização. Quando a violência se rege pela relação meios/fim, o problema maior é que não só os fins justifiquem os meios, mas, como diz Arendt (1975), os meios possam dominar os fins, fato muito freqüente hoje em dia, em que a disposição de meios tecnológicos sofisticados faz com que os efeitos do seu uso escapem ao controle de seus usuários: o Estado, os movimentos insurrecionais ou os autores de atentados terroristas. A disseminação direta ou indireta desses meios, que acabam tornando-se "necessários" na solução dos conflitos, constitui a causa principal da dificuldade de controlar a violência social no mundo contemporâneo e torna mais complexa sua explicação. Saber que o outro pode fazer uso desses meios conduz ao armamento geral dos espíritos, gerando o ciclo infernal da "escalada da violência".

Uma questão importante e desafiadora é saber se a violência pode ser racionalmente explicada. $\mathrm{Na}$ medida em que ela é uma qualidade de certos atos humanos, inseridos no repertório das condutas sociais, deve ser explicável. Todavia, existem alguns obstáculos epistemológicos, para usar os termos de Bachelard (1972), que dificultam sua explicação, quando ela colide com os conceitos que se tem dos aspectos que compõem a problemática social e dos atos humanos.

Duas grandes questões constituem o eixo das diferentes explicações do fenômeno da violência. A primeira diz respeito à sua origem: a violência é a manifestação de tendências instintivas ou pulsionais ou, ao contrário, é um comportamento adquirido na vida social por meio de um processo qualquer de aprendizagem. Neste caso, o problema da violência se insere no debate das relações entre o inato e o adquirido, entre a natureza e a cultura. Esse debate secular ainda divide os principais sistemas explicativos dos comportamentos humanos. A segunda 
questão diz respeito à sua natureza: trata-se de um fenômeno normal ou é a expressão de um estado anormal (falha, deficiência ou disfunção) do indivíduo ou do seu meio social? Colocar assim o problema é bastante complicado, pois introduz a difícil questão do fundamento científico dos critérios definidores do normal e do anormal no campo das condutas humanas e da legitimidade desse ato definidor, particularmente quando a anormalidade é entendida como sinônimo de patologia mental ou social.

A idéia de que a violência é de natureza instintiva ou pulsional, conforme a perspectiva teórica que se adote, está fortemente arraigada no pensamento moderno. A representação do mal como um componente da natureza humana é muita antiga. Ela encontra suporte nos grandes sistemas religiosos e morais que marcaram a história humana, em particular o judaísmo e o cristianismo. Eco dessa representação é o célebre refrão homo homini lupus ("o homem é lobo para o homem"), que serviu de fundamento à filosofia política de Thomas Hobbes (2003), no Leviathan (1651). A esse respeito, diz Freud (1968, p. 37-38):

Quem se atreveria a refutar este refrão após todas as experiências da vida e da História? Via de regra, esta cruel agressão só espera ser provocada para desencadear-se, quando não se põe a serviço de outros propósitos cujo objetivo poderia ser igualmente alcançado com meios menos violentos. Em condições favoráveis, quando desaparecem as forças psíquicas antagônicas que de forma geral a inibem, ela pode também manifestarse espontaneamente, desmascarando o homem como besta selvagem que não conhece o menor respeito pelos seres da sua própria espécie.

A teoria freudiana das pulsões faz da "pulsão de morte" a fonte das tendências destrutivas do homem. Eros e Thanatos (Amor e Discórdia) são, para Freud, que segue a perspectiva do dualismo moral, os dois grandes protagonistas míticos que regem o drama da existência humana.

A tese da origem instintiva ou pulsional da violência foi reforçada por trabalhos científicos aparecidos nos campos da biologia e da etologia a partir dos anos de 1960 (Lorenz, 1960; Tinbergen, 2006; Andrey, 1961, 1966; Dart, 1959; Morris, 1967, 1969; Storr, 1968, 1972; Johnson, 1972). A grande objeção às teses ecológicas do instinto é sua transposição ao campo das relações sociais humanas. Como o mostram alguns especialistas (Chance, 1974), a estrutura social das 
numerosas espécies que compõem as chamadas sociedades agonísticas está fundada em certos mecanismos instintivos que delimitam o campo da agressão individual no mundo animal às condutas adaptativas das espécies: a competição, que assegura a sobrevivência da espécie sem pôr em grave risco a existência do indivíduo; a dominância, que garante a manutenção de um sistema de hierarquias necessário à estabilidade e à paz do grupo; e a defesa do território, responsável pelo equilíbrio entre população e habitat. Se, no mundo animal, esses mecanismos se revelam altamente úteis, a sua transposição para o campo social humano, onde a emergência do simbólico torna dessuetos os mecanismos instintivos, não encontra suficiente fundamentação científica. Fazer da competição, da hierarquia e da defesa do território características da natureza humana só serve para justificar a violência social de uns e condenar a hostilidade de outros.

A respeito do caráter "normal" ou "anormal" da violência, vale lembrar as análises de Durkheim, no seu livro clássico de 1937, As regras do método sociológico, ${ }^{2}$ onde utiliza o exemplo do crime para mostrar a aplicação dessas regras numa sociologia positiva dos "fatos sociais", colocando algumas idéias relativamente polêmicas. A principal delas é que o crime é um fato da sociologia normal, pois ele faz parte de qualquer tipo de sociedade (1937, p. 15), aparecendo "estreitamente ligado às condiçôes de toda vida coletiva": "Classificar o crime entre os fenômenos da sociologia normal não é apenas dizer que é um fenômeno inevitável, embora lamentável, devido à incorrigível maldade dos homens; é afirmar que ele é uma parte integrante da sociedade sã” (ibid., p. 66).

O que Durkheim quer demonstrar é que o crime faz parte de toda organização social humana, sem o qual nenhuma sociedade seria possível. Se relacionarmos a questão da liberdade à condição bumana do homem, tal como é visto neste texto, pode-se concluir que quem cria as regras e as leis de convivência social deve poder, pela mesma razão, transgredi-las, mesmo sendo isso algo que é indesejável e reprovado pela consciência social (moral?) dos outros. Numa sociedade humana, o crime é condição de existência da lei e esta é condição de existência do crime, fatos contrários que se relacionam de uma forma dialética. O que não é tão fácil compreender é que o crime possa ser um "fator de saúde pública", como diz Durkheim, embora sua argumentação siga uma lógica impecável. Com efeito, o autor relaciona o 
crime com os sentimentos e valores que protegem o direito penal de um povo. Ora, afirma ele:

Para que numa dada sociedade os atos considerados criminosos possam deixar de ser cometidos, seria necessário que os sentimentos que eles ferem existissem em todas as consciências individuais sem exceção e num grau de força capaz de conter os sentimentos contrários. Ora, supondo que essa condição pudesse ser efetivamente realizada, o crime não desapareceria por isso, ele mudaria apenas de forma, já que a própria causa que fechasse dessa maneira as fontes da criminalidade abriria outras novas. (Ibid., p. 67)

Por quê? Caberia perguntar-se. A explicação não parece tão difícil, se seguirmos com um exemplo o argumento do autor. Para acabar com os crimes comuns, por exemplo, não basta encerrar seus autores numa cadeia. É necessário, segundo Durkheim, que o sentimento contrário a esses crimes se torne maior que o a vontade de cometê-los nos meios sociais onde se recrutam os criminosos. Todavia, para que isso ocorra é necessário que o sentimento de aversão produzido pelo crime cresça também no conjunto da sociedade. Mas, se isso acontecer e novos crimes mais graves forem cometidos, é necessário que esse sentimento cresça também na sociedade, pois o nível do sentimento anterior não seria suficientemente forte para ter o sentimento de aversão das novas formas de crime. Em outros termos, quanto mais elevados forem os valores que o crime viola, tanto mais fortes devem ser os sentimentos contrários que ele desperta na consciência social dos homens. Caso contrário, o crime acabaria tomando conta da sociedade. Nesse sentido, a conclusão de Durkheim de que é um fator de saúde para a sociedade parece sustentável.

Essas análises de Durkheim sobre o crime teriam alguma utilidade para pensar o fenômeno da violência em geral e, em especial, a que ocorre hoje no Brasil? Em alguns aspectos, sim; em outros, não. Seguramente, não é aplicável no que diz respeito ao ponto central da argumentação. Se o crime é necessário - ou seja, "normal” porque é inerente à natureza da sociedade -, a violência não o é, pois não faz parte da natureza da sociedade. Se não é possível uma sociedade sem crimes, é perfeitamente possível, embora possa ser utópico, pensar numa sociedade sem violência. Mas parece que é aplicável no que diz respeito à relação que deve existir entre a prática da violência e o grau 
de consciência de repulsa da sociedade. Como no caso do crime, para erradicar a violência não bastam a sua repressão e a reclusão dos seus autores ou, pior ainda, o seu extermínio. O que é necessário é que a consciência do sentimento de repulsa não só atinja seus autores, mas que aumente na sociedade como um todo, na proporção do aumento intensivo e extensivo das ações violentas. Duas coisas ameaçam a eliminação da violência na sociedade: uma, o recuo da consciência do sentimento de repulsa social, por cansaço, banalização da violência ou por submissão às suas regras como algo inevitável, por não vislumbrar soluções eficazes; outra, apostar na repressão e eliminação intencional ou "acidental" dos seus autores, utilizando todos os meios físicos necessários "legais", mesmo violentos. No primeiro caso, é a rendição às regras da violência; no segundo, é a escalada da violência, em que todos serão perdedores. Tomara que o caminho do bom senso prevaleça: eliminar as condições reais, sociais, econômicas e políticas que geram a violência.

\section{Violência e educação ${ }^{3}$}

Considerada a violência como um fenômeno, ao mesmo tempo social - por ter a ver com as condiçóes históricas da sociedade que estabelece os limites das ações humanas - e individual - por ter a ver com o foro interno de cada indivíduo que decide respeitar ou não esses limites -, pode-se dizer que praticar ou não a violência, mesmo em situações de difícil escolha (por dissentir, por exemplo, da justiça ou da legitimidade da ordem social em que tudo isso tem lugar), é um aspecto do livre agir humano (se não for negado o princípio do livre arbítrio) susceptível de educação, uma vez que não há nada, nem do ponto de vista genético, nem do ponto de vista do meio físico ou social, que determine esse agir.

Falar em educação, na perspectiva de um humanismo laico, é falar da constituição humana do homem ou, em outros termos, da sua constituição cultural, entendendo por isso o processo pelo qual um ser naturalmente biológico se transforma num ser cultural, pela interiorização da experiência social e cultural dos homens, vivida no seio do grupo humano em que está inserido. Entendida assim, a educação do homem não ocorre num locus preciso, mas na totalidade das situações em que essa experiência é vivida. Salientando, porém, que o fundamental dessa experiência constitutiva do ser cultural do homem se situa no 
plano das relaçóes sociais em que ele está envolvido ao longo da sua vida. É a consciência da necessidade de estabelecer e de viver essas relações que constitui a razão de base da não-violência. Educar para a "não-violência" é, portanto, ajudar as novas gerações a encontrarem as razões suficientes para não optar pela violência que ameaça inviabilizar essas relações. A questão então é saber quais são essas razões e qual é seu poder de persuasão para evitar a violência.

Sabemos que, no pensamento ocidental, as razões morais para praticar o bem e evitar o mal (e tudo que cada um desses conceitos representa) têm sido, historicamente, de natureza religiosa, fazendo do desejo do prêmio (qualquer que este seja) e do medo do castigo (qualquer que este seja) um princípio educativo fundamental. A chance de escapar do castigo tem sido, por sua vez, um poderoso incentivo para fazer o mal e deixar de praticar o bem. Essa experiência de educação moral predominante secularmente no ocidente ajuda a entender, se não a explicar, a eficácia do estatuto da "impunidade" das ações violentas e criminosas na moral laica da era contemporânea. Essa "impunidade” nada mais é que o jogo da "moral imoral" ou de uma imoralidade que se oculta por trás da aparência de moralidade. Não é necessária muita genialidade para perceber duas coisas: que um tal princípio educativo só pode levar ao fracasso da educação e que a educação para a "nãoviolência” exige razões muitos mais sólidas e fundantes do que essas que levam tantos ao velho jogo da "moral imoral". A dúvida atroz que surge é se o recurso contemporâneo às questôes éticas, substituto laico do recurso às velhas questôes da moral religiosa, não conduz a esse mesmo jogo. A experiência das "comissões de ética", tão freqüentes na época contemporânea, junto com outras práticas políticas de manipulação das leis e das normas, ajuda a desfazer essa dúvida. Diante desses e de outros fatos semelhantes, é ainda possível falar em educação para a nãoviolência?

Talvez o leitor se pergunte: $\mathrm{O}$ assunto em debate não é a violência? Que têm a ver isso com as questôes de moral e de ética e os casos, que certamente são inúmeros, em que se aplica o jogo da "moral imoral"? Fazendo deste jogo, cujo sentido metafórico não diminui seu sentido de realidade, o ponto central do debate, pode-se dizer que ele traduz uma das faces da consciência que se julga estar acima e além de toda lei e de todo limite: agir cinicamente para atingir os objetivos pessoais, evitando o uso de meios que possam parecer ou ser entendidos 
pelos outros como violentos. A outra face do jogo da "moral imoral" é utilizar, sem cinismos, todos os meios disponíveis para atingir o objetivo visado. Sentir-se no "direito" de poder violar a lei e todos os limites, seja recorrendo aos meios violentos, seja no silêncio cínico da má consciência, é uma forma equivalente de violência, embora diferente quanto à dramaticidade dos cenários possíveis. Ambas as faces de que pode revestir-se a violência social revelam o fracasso da ação educativa na sociedade humana, tanto no meio social em que operam os indivíduos, quanto nesse meio particular que é a escola. Na medida em que essas práticas se disseminarem na sociedade, particularmente nos centros do poder político, delegado, não se esqueça, pela sociedade, podese pensar que a consciência moral ou ética da sociedade como um todo está ao ponto de entrar em colapso, se nada for feito para impedi-lo eficazmente.

Por ser a violência um problema da sociedade como um todo, particularmente quando atinge determinados patamares de intensidade, ela repercute logicamente no meio escolar, de várias maneiras e por várias razões. As várias maneiras se sintetizam nos seguintes cenários: atos de violência e/ou de vandalismo contra a escola e seus integrantes, perpetrados por agentes externos a ela; atos de violência na escola, seja praticados por agentes internos a ela, seja pela presença em seu interior de agentes externos; e, enfim, atos explícitos ou implícitos de violência praticados pela escola ou seus dirigentes (Pino, 1995). As razões disso são várias, podendo ser lembradas as principais: (1) A escola é, em certo sentido, uma espécie de caixa de ressonância das turbulências sociais que ocorrem nos diferentes meios sociais de onde procedem seus integrantes. Embora seja condenável qualquer prática de discriminação de alunos em função do lugar de procedência (periferias, favelas e bairros operários), que tem muito a ver com a condiçãao social de classe, é inegável que a convivência deles com o clima de violência que pode existir nesses meios afeta de alguma maneira sua vida na escola. (2) O fato de ser a escola uma instituição frequentemente alheia ao que ocorre no meio social em que está inserida provoca um certo distanciamento entre ela e o próprio meio, o que a torna um "objeto" estranho para este meio e alvo fácil de ações predatórias, além de ser um espaço predileto de circulação de produtos legalmente proibidos, como as drogas. (3) Sem pretender desqualificar a escola, parece existir um certo consenso a respeito do fato de que a escola de hoje continua praticamente a 
mesma de séculos anteriores, imobilizada frente às mudanças que vêm ocorrendo na sociedade. Conseqüentemente, as relaçôes entre os vários corpos que a compõem (direção ó docentes; docentes ó discentes; direção ó discentes) mudaram também, criando um mal-estar, de proporções que variam em cada escola, com consequências negativas nas relações entre eles. Isso facilita a emergência no interior da instituição escolar de formas de conduta, outrora impensáveis, nas relações sociais de alguns dos seus integrantes. (4) Os dirigentes da escola (direção, administração e corpo docente), com honrosas exceções, parecem não ter o feeling necessário para entender os "sinais dos tempos", de que fala Medeiros (1998) numa pesquisa em meio escolar, que lhes permita entender o que está acontecendo com os alunos e com os agentes perturbadores externos. (5) A instituição escolar traduz em si mesma, em maior ou menor grau, os processos e mecanismos históricos de exclusão social das crianças e jovens das classes populares. Não é de se admirar então que a instituição estranhe esses alunos, que em algumas escolas são maioria absoluta, e que esses alunos estranhem a instituição, abrindo-se assim no interior da escola o caminho para ações predatórias internas e para a emergência de formas com características aberta ou veladamente violentas. Pode-se dizer então que, se a escola, como outras instituições sociais, muito pode fazer para incentivar a compreensão por parte dos alunos dos valores realmente humanos, livres de qualquer afetação moralista, capazes de fornecer razões para não optar pelo uso da violência no intuito de viver uma sociabilidade humana, ela tem também que repensar sua função numa sociedade em constante mudança.

Termino repetindo o que já foi dito anteriormente: "se a educação não é a solução para acabar com a violência, sem educação a violência não tem solução, nem a curto nem a longo prazo". Eis o desafio que se abre.

Recebido em junho de 2007 e aprovado em julho de 2007.

\section{Notas}

1. Estou me referindo à Criminologia Crítica, também conhecida como Nova Criminologia, movimento acadêmico que contrapõe às explicações tradicionais do crime e da violência uma visão crítica do Estado moderno e de suas Leis, que fazem dos indivíduos das classes populares o alvo principal da repressão ao crime e à violência. A obra de Ian Taylor, Paul 
Walton e Jock Young, The new criminology: for a social theory of deviance, publicada na Inglaterra em 1973, representa o início de um movimento em criminologia que acabou afetando alguns setores das ciências jurídicas.

2. Refiro-me à obra clássica de Emile Durkheim, Les règles de la méthode sociologique, publicada em 1937 e que tem por objetivo estudar do método em sociologia, escolhendo o caso particular do "crime" como exemplo de um fato social em que se pode fazer uma aplicação dessas regras ( $3^{\circ}$ cap., item III).

3. Este tema é objeto do texto do prof. Miguel Gonzalez Arroyo, "Quando a violência infantojuvenil indaga a Pedagogia”, com o qual o presente artigo constitui um conjunto temático neste número de Educação \& Sociedade.

\section{Referências bibliográficas}

ANDREY, R. African genesis. New York: Atheneum, 1961.

ANDREY, R. The territorial imperative. New York: Atheneum, 1966.

ARENDT, H. On violence (1969). Brasilia, DF: UNB, 1975.

BACHELARD, G. La formation de l'esprit scientifique. Paris: Vrin, 1972.

BALL-ROKEACH, S.J. Normative and deviant violence from a conflict perspective. Social Problems, Washington, v. 28, n. 1, p. 45-62, oct. 1980 .

BUARQUE DE HOLANDA, A.F. Novo Dicionário da Lingua Portuguesa. Rio de Janeiro: Nova Fronteira, 1975.

CAILLOIS, R. L'homme et le sacré. Paris: Gallimard, 1950.

CHANCE, M. Sociétés hédoniques et sociétés agonistiques chez les primates. In: Morin, E.; Palmarini, M.P. (Org.). L' unité de l'homme. Paris: Seuil, 1974. v. 1, p. 83-91.

DART, R. Adventures with the missing link. New York: Harper \& Row, 1959.

DURKHEIM, E. As regras do método sociológico. Trad. J. Rodrigues Meréje. São Paulo: Brasileira, 1937.

ESQUIROL, E. Des maladies mentales. Paris: J.B. Baillière, 1838.

FOUCAULT, M. L'histoire de la folie à l'àge classique. Paris: Gallimard, 1972.

Educ. Soc., Campinas, vol. 28, n. 100 - Especial, p. 763-785, out. 2007

Disponível em <http://www.cedes.unicamp.br> 
FOUCAULT, M. Surveiller et punir. Paris: Gallimard, 1975.

FREUD, S. El malestar en la civilización. In: Freud, S. Obras completas. Madrid: Biblioteca Nueva, 1968. p. 37-38.

GIRARD. R. La violence et le sacré. Paris: Grasset, 1972.

HACKER, F. Agression et violence dans le monde moderne. Paris: Calmamm-Levy, 1972. p. 89.

HOBBES, T. Leviatã ou a matéria, forma e poder de um estado eclesiástico e civil. Trad. Rosina D’Angina. 2. ed. São Paulo: Ícone, 2003.

JOHNSON, R.N. A agressão nos homens e nos animais. Rio de Janeiro: Interamericana, 1972.

LEGENDRE, P. L'amour du censeur. Paris: Seuil, 1974.

LOMBROSO, C. L'Uomo delinquente. Milan: Hoepli, 1876.

LORENZ, K. On aggression. New York: Harcourt, Brace \& World, 1960 .

LORENZ, K. L'agression: une histoire naturelle du mal. Paris: Flammarion, 1969.

MAKARIUS, L.L. Le sacré et la violation des interdits. Paris: Payot, 1974.

MEDEIROS, S.D. Sinais dos tempos: marcas da violência em diferentes modos de linguagem da criança. Campinas: Autores Associados, 2002 .

MONTAGU, A. A natureza da agressividade humana. Rio de Janeiro: Zahar, 1978.

MORIN, E. Le paradigme perdu: la nature humaine. Paris: Seuil, 1973.

MORRIS, D. The naked ape. New York: McGraw-Hill, 1967.

MORRIS, D. The human zoo. New York: McGraw-Hill, 1969.

PINO, A. Direito e realidade social da criança no Brasil. Educação \& Sociedade, Campinas, v. 11, n. 36, p. 61-79, 1990. 
PINO, A. Violence in the schools in Brazil. Thresholds in education, Wilmington, n. 2, p. 11-17, 1995.

PINO, A. Prefácio: Violência, racionalidade e ordem social. In: Medeiros, S.D. Sinais dos tempos: marcas da violência em diferentes modos de linguagem da criança. Campinas: Autores Associados, 2002.

PRICHARD, J.B. A treatise on insanity and other disorder affecting the mind. London: Gilbert Pipper, 1835.

STORR, A. Human aggression. New York: Atheneum, 1968.

STORR, A. Human destructivennes. New York: Basic Books, 1972.

TINBERGEN, N. Social behavior in animals: with special reference to vertebrates. Jodhpur: J.V., 2006. 